\title{
Phytochemical Investigation, Fatty Acid Analysis and In Vitro Membrane Stabilizing Activity of the Roots of Amaranthus spinosus L.
}

\author{
Md. Rubel Al Mamun ${ }^{1}$, Tasnim Ahmed ${ }^{2}$, Md. Selim Aktar Reza ${ }^{1}$ and Md. Hasanur Rahman ${ }^{1 *}$ \\ ${ }^{1}$ Department of Chemistry, University of Dhaka, Dhaka-1000, Bangladesh \\ ${ }^{2}$ Department of Genetic Engineering and Biotechnology, University of Dhaka, Dhaka-1000, Bangladesh
}

(Received : 1 February 2021; Accepted : 24 February 2021)

\begin{abstract}
Ethylacetate extract of the roots of Amaranthus spinosus L. was subjected to phytochemical investigation and three compounds stigmasterol, 1-Eicosanol and oleic acid were isolated in pure state. The $n$-hexane extract was analysed for fatty acid with GC-FID and four saturated fatty acids; caprylic acid, stearic acid, arachidic acid and behenic acid, and four unsaturated fatty acids; palmitoleic acid, oleic acid, linoleic acid and erucic acid were identified and quantified. Different extracts were assessed to explore their in vitro membrane stabilizing activity using standard protocol. Methanol extract of A. spinosus showed $68.13 \%$ inhibition in hypotonic solution-induced hemolysis and $74.53 \%$ inhibition in heat induced hemolysis which was the highest than its other Kupchan fractions. Acetyl salicylic acid was used as standard that showed $42.00 \%$ inhibition of hemolysis at normal condition.
\end{abstract}

Keywords: Secondary metabolites, Membrane stabilizing activity, Fatty acids.

\section{Introduction}

Amaranthus spinosus L. is a medicinal plant of Amaranthaceae family found in tropical, subtropical and Himalayan region ${ }^{1}$. In Bangladesh it is known as katanotey (Chittagong), khuira kata (Mymensingh) according to the Bangladesh Ethnobotany online database ${ }^{2}$. It is an erect, monoecious herb, up to $100-130 \mathrm{~cm}$ tall grows annually as a weed in cultivated as well as fallow lands ${ }^{3}$. This plant is used as food in different tropical countries, especially tribal and mass people ${ }^{4}$. This plant has been reported to have some pharmacological properties. It's used in traditional medicines are very effective, have lower side effects, are accessible and affordable with low cost. It is used as antipyretic, laxative, stomachic, febrifuge traditionally ${ }^{5}$. The seed of it is used as a poultice for broken bones and the root of it is used to treat gonorrhoea $^{6}$. It has been reported in modern scientific analysis that it has anti-depressant activity, anti-diabetic properties, anti-inflammatory activity, immunomodulatory activity, antibacterial property, anti-hyperlipidemic, spermatogenic activity, anti-malarial and effect on hematology ${ }^{7-12}$. A. spinosus is a good source of fatty acids such as stearic acid, oleic acid, palmitic acid, linoleic acid ${ }^{4,5}$. The plant contains some bioactive phytochemicals like nalkanes, octacosanoate, hentriacontane, sterols including fatty acids, free alcohols, $\alpha$-spinasterol, $\beta$-sitosterol, campesterol, cholesterol, stigmasterol, proteins and mixture of saponins, D-glucose and D-glucuronic acid. It is a good source of calcium and also contains phosphorous, iron, nicotinic acid, ascorbic acid and protein ${ }^{5,13}$.

Previously less attention was observed on membrane stabilizing activity of A. spinosus. As they contain significant antioxidant ${ }^{10}$ properties, they might have membrane stabilizing activity. Therefore, based on the evidence found from literature survey the present study was taken to investigate the phytochemicals and fatty acid analysis of the roots of $A$. spinosus and in vitro membrane stabilizing activity.

\section{Experimental}

\section{Collection of the plant materials}

The roots of the plant were collected from Gazipur, Bangladesh and taxonomic identification was made by the Department of Botany, University of Dhaka. The collected roots were cleaned to remove mud and dust particles. The roots were dried at room temperature followed by in an oven below $40^{\circ} \mathrm{C}$. A grinder (Cyclotec 200 meshes) was used to grind the dried roots to powder. The root powder was stowed in an airtight bottle and used during the investigations.

\section{Phytochemical screening}

To identify the phytoconstituents such as tannin, phlabotannins, alkaloid, saponin, flavonoid, steroid, terpenoid, and cardiac glycoside etc. different phytochemical tests were done using standard protocols ${ }^{14}$.

\section{Extraction}

The powdered roots of $A$. spinosus (360 g) were extracted with n-hexane followed by ethyl acetate (EtOAc). Using filter paper through a funnel these extracts were filtered separately and the filtrates were evaporated to dryness with a rotary evaporator (Stuart, UK) under reduced pressure temperature of $40^{\circ} \mathrm{C}$. Ethyl acetate extract $(\sim 3.10 \mathrm{~g})$ was used for phytochemical investigation and $n$-hexane extract was kept for fatty acid analysis.

\section{Isolation of phytochemicals from EtOAc extract}

The crude EtOAc extract was exposed to TLC screening and it demonstrated several spots in iodine chamber and vanillin sulfuric acid spray on TLC plate. The dry mass of EtOAc extract $(3.10 \mathrm{~g})$ was subjected to column chromatography over column grade silica gel (Kiesel gel $60 \mathrm{G})$. At first the column was eluted with $100 \%$ hexane and then eluted with mixtures of hexane with increasing amount of dichloromethane, and finally with increasing methanol. The effluents were collected in $250 \mathrm{~mL}$ conical flask where

*Author for correspondence. e-mail: hasanur@du.ac.bd 
12 fractions marked as $\mathrm{P}_{1}, \mathrm{P}_{2}, \mathrm{P}_{3}, \mathrm{P}_{4}, \mathrm{P}_{5}, \mathrm{P}_{6}, \mathrm{P}_{7}, \mathrm{P}_{8}, \mathrm{P}_{9}, \mathrm{P}_{10}$, $\mathrm{P}_{11}$, and $\mathrm{P}_{12}$ were obtained according to TLC pattern. Among the fractions $\mathrm{P}_{8}$ was observed as a single spot. So, the fraction $\mathrm{P}_{8}$ was allowed to stand for hours and white crystalline compound was obtained which was marked as $\mathbf{1}$. The fraction $\mathrm{P}_{9}$ appeared to contain three spots. The fraction $\mathrm{P}_{9}$ was further subjected to sub column for re-fractionation by column chromatography. A total of seven fractions were collected based on their TLC pattern and marked as $F_{1}, F_{2}$, $\mathrm{F}_{3}, \mathrm{~F}_{4}, \mathrm{~F}_{5}, \mathrm{~F}_{6}$ and $\mathrm{F}_{7}$. Among them, F5 produced another white crystalline compound which was marked as 2 . The fraction $\mathrm{F}_{6}$ was observed two spots with distinct $\mathrm{R}_{\mathrm{f}}$ value. From $\mathrm{F}_{6}$ a compound was separated and purified by preparative thin layer chromatography (PTLC) and was marked as $\mathbf{3}$.

\section{Analysis of fatty acids}

n-hexane extract of $A$. spinosus was subjected to fatty acid (FA) analysis. Both free fatty acids (FFAs) and bound fatty acids (BFAs) were extracted from the plant and converted into their corresponding methyl ester to make the volatile to be capable of being analyzed by gas liquid chromatography (GC).The prepared methyl ester of FFA and BFA along with standard fatty acids ester samples were analyzed by GLC (Shimadzu 9A, Column-BP-50, Detector-FID, $105^{\circ} \mathrm{C}$ $5^{\circ} \mathrm{C} / \mathrm{min}-150^{\circ} \mathrm{C}-2^{\circ} \mathrm{C} / \mathrm{min}-280$ ) and their retention time was recorded. The relative percentages of the FFAs and BFAs were calculated from peak area.

\section{Membrane stabilizing activity}

$200 \mathrm{~g}$ dried powder of A. spinosus root was soaked in 1000 $\mathrm{mL}$ of methanol for 7 days with occasional shaking and filtered through a cotton plug followed by Whatman filter paper number 1 . The filtrate was dried using a rotary evaporator under reduced pressure evaporator at low temperature. $5 \mathrm{~g}$ of the dried extract of A. spinosus was subjected to solvent-solvent partitioning following the modified Kupchan method ${ }^{15}$ to yield n-hexane, dichloromethane, chloroform and aqueous soluble fractions. Then the crude methanol extract and its concentrated Kupchan fractions were evaluated for membrane stabilizing activity.

\section{Results and Discussion}

Three compounds were isolated (1-3) from the EtOAc extract of the roots of A. spinosus by column chromatography and preparative thin layer chromatography.

\section{Characterization of compound-1}

Physical appearance of the compound-1 was colorless, crystalline solid having $R_{F}$ value of 0.80 in (98\% DCM: $2 \%$ $\mathrm{MeOH}$ ) and its melting point was found to be $158-160^{\circ} \mathrm{C}$. It dissolved in dichloromethane, chloroform. The ${ }^{1} \mathrm{H}-\mathrm{NMR}$ (400 $\mathrm{MHz}$, in $\mathrm{CDCl}_{3}$ ) spectrum of the compound-1 showed two sharp singlets (s) at $\delta 0.58$ and 1.04 ppm typical for the presence of methyl protons at C-18 and C-19 respectively and multiplet at $\delta 3.62 \mathrm{ppm}$ indicated of the presence of oxymethine proton (H-3). Two downfield signals at $\delta 5.04$ and $\delta 5.15 \mathrm{ppm}$ revealed the presence of olefinic protons at C-22 and C-23 respectively. A broad singlet at $\delta 1.28 \mathrm{ppm}$ was due to the presence of methyl proton at C-29. The other signals of the spectrum between $\delta 1.05-2.06 \mathrm{ppm}$ were due to the presence of different methylene $\left(-\mathrm{CH}_{2}-\right)$ and methine (>CH-) protons. The ${ }^{13} \mathrm{C}-\mathrm{NMR}$ spectrum of compound-1 showed the presence of twenty-nine (29) carbon signals. The signals at $\delta 139.58,138.16,129.47$ and $117.47 \mathrm{ppm}$ were due to for olefinic carbons and signals at $\delta 40.81$ and $37.17 \mathrm{ppm}$ were assignable to two quaternary carbons. The signals at $\delta 71.08 \mathrm{ppm}$ give indication of oxymethine carbon. From the physical characteristics and spectral analysis $\left({ }^{1} \mathrm{H}-\mathrm{NMR}\right.$ and $\left.{ }^{13} \mathrm{C}-\mathrm{NMR}\right)$ data of the compound-1 and comparing the reported value ${ }^{16}$ of ${ }^{1} \mathrm{H}-\mathrm{NMR}$ and ${ }^{13} \mathrm{C}$ NMR spectral data of stigmasterol, the structure of the compound was established as stigmasterol.

\section{Characterization of compound-2}

Compound-2 ( $3.5 \mathrm{mg}$ ) was a colorless semi solid having $\mathrm{R}_{\mathrm{F}}$ value 0.65 (in $70 \%$ DCM: $30 \%$ Hexane) and its melting point was found to be $58-60{ }^{\circ} \mathrm{C}$. It was soluble in dichloromethane. The ${ }^{1} \mathrm{H}-\mathrm{NMR}$ (400 $\mathrm{MHz}$, in $\mathrm{CDCl}_{3}$ ) spectral peak of the isolated compound-2 at $\delta 0.90$ ppm was indicative of methyl group. A strong sharp peak at $\delta 1.28$ ppm was due to the presence of methylene protons at C-3 to $\mathrm{C}-19[\mathrm{H}-3$ to $\mathrm{H}-19]$. The signal at $\delta 1.59 \mathrm{ppm}$ was due to the presence of proton at $\mathrm{C}-2(\mathrm{H}-2)$. The signal at $\delta 3.66$ ppm was due to the methylene proton adjacent to $\mathrm{C}-1$ containing $-\mathrm{OH}$ group. The ${ }^{13} \mathrm{C}-\mathrm{NMR}$ spectrum of the compound-2 showed the presence of 20 carbons. The signal at $\delta 63.12 \mathrm{ppm}$ was due to the alcoholic carbon $(>\mathrm{CH}-\mathrm{OH})$ at $\mathrm{C}-1$. The signal at $\delta 32.83 \mathrm{ppm}$ is assignable to methylene carbon attached to $\mathrm{C}-1$. Six signals between $\delta$ 22.69- $31.93 \mathrm{ppm}$ were due to the presence of methylene ($\mathrm{CH}_{2}$ ) carbon and the signal at $\delta 14.10 \mathrm{ppm}$ was assignable to methyl carbon at C-20. All these ${ }^{1} \mathrm{H}-\mathrm{NMR}$ and ${ }^{13} \mathrm{C}$ NMR spectral data of compound-2 was in good agreement with the reported data ${ }^{\mathbf{1 7}, 18}$ of 1-Eicosanol and the compound-2 was established as 1-Eicosanol.

\section{Characterization of compound-3}

Physical state of the compound-3 ( $3.2 \mathrm{mg})$ was a whitesemi solid having $R_{F}$ value 0.75 (in $70 \%$ DCM: $30 \%$ Hexane). The compound was soluble in dichloromethane. On spraying with vanillin-sulfuric acid spray reagent, followed by heating at $110{ }^{\circ} \mathrm{C}$ for several minutes and violet color was appeared. The IR spectrum of the compound-3 revealed absorption band at 2954, 2849, 1707, $1631,1472,1434$ and $719 \mathrm{~cm}^{-1}$. IR absorption band at 2954 $\mathrm{cm}^{-1}$ and at $1707 \mathrm{~cm}^{-1}$ were assignable to $\mathrm{O}-\mathrm{H}$ stretching and carbonyl group $(\mathrm{C}=\mathrm{O}$ stretching), respectively. The absorption band at $1434 \mathrm{~cm}^{-1}$ was indicative to $\mathrm{O}-\mathrm{H}$ bending. The ${ }^{1} \mathrm{H}-\mathrm{NMR}$ (400 $\mathrm{MHz}$, in $\mathrm{CDCl}_{3}$ ) spectrum of the isolated compound-3 had a peak at $\delta 0.90 \mathrm{ppm}$ indicative of three protons of one methyl group. A strong sharp peak at $\delta 1.28 \mathrm{ppm}$ was due to the presence of methylene protons at $\mathrm{C}-4$ to $\mathrm{C}-7$ and $\mathrm{C}-12$ to $\mathrm{C}-16$. The band at $\delta 2.37 \mathrm{ppm}$ was due to the presence of proton at C-2 
( $\alpha$-carbon). The band at $\delta 5.38 \mathrm{ppm}$ was due to the proton attached with unsaturated carbon. All these FT-IR and ${ }^{1} \mathrm{H}$ NMR data was good agreement with the reported data ${ }^{19}$ of oleic acid. Hence the compound-3 was confirmed as oleic acid.

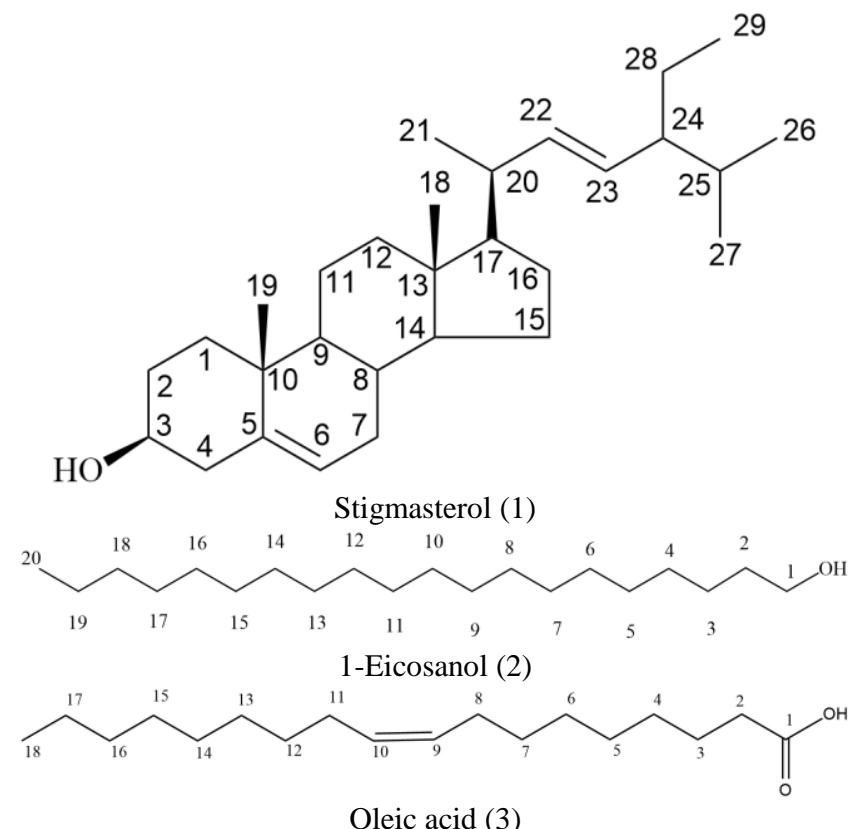

Fig. 1. Structure of isolated compounds

\section{Fatty acid analysis}

$431 \mathrm{mg}$ of $\mathrm{n}$-hexane extract was dissolved in n-hexane followed by extraction with $5 \%$ sodium bicarbonate solution. The mixture was taken in a separatory funnel \& shaken vigorously and two layers were obtained. The lower layer (aqueous) and the upper layer were separated for the analysis of FFA and BFA respectively. Both types of FAs of the roots were converted to their methyl esters for analyzing by gas liquid chromatography (GLC). The prepared methyl ester of FFAs and BFAs along with standard fatty acids ester samples were subjected to GLC and their retention time was recorded. In the plant, four saturated fatty acids (SFAs); caprylic acid, stearic acid, arachidic acid and behenic acid, and four unsaturated fatty acids (USFAs); palmitoleic acid, Oleic acid, Linoleic acid and erucic acid were identified. USFAs were higher amount than the SFAs. Similarly, total amount of BFAs $(117 \mathrm{mg})$ were higher than the total amount of FFAs $(29 \mathrm{mg}$ ). The analysis of BFAs showed that $A$. spinosus contains highest proportion of stearic acid (26.45 $\%$ ), and lowest proportion of arachidic acid (1.84\%) and others as palmitoleic, oleic, erucic, linoleic, caprylic behenic acids are present with intermediate percentage of 24.12, $19.02,11.20,7.82,5.10$ and $4.43 \%$ respectively. The analysis of FFAs disclosed that palmitoleic acid is the most abundant $(30.40 \%)$ FA present in free form in the roots of A. spinosus. and erucic, stearic, behenic, oleic, linoleic, caprylic, arachidic acids are the other FAs present with an intermediate percentage of $23.45,12.83,10.19,8.38,8.37$, 4.44 and $1.94 \%$ respectively.

\section{Evaluation of membrane stabilizing activity}

Anti-inflammatory activity of methanolic extracts and their different fraction of the roots of A. spinosus were assessed by following the method ${ }^{20}$ of hypotonic and heat induced hemolysis of human erythrocyte using aspirin as standard. The maximum level of membrane stabilizing activity was observed by methanol extract in both hypotonic solutioninduced hemolysis $(68.13 \%)$ and heat induced hemolysis $(74.53 \%)$. In hypotonic solution-induced hemolysis, nhexane fraction (HF) inhibited $39.94 \%$, chloroform fraction (CHF) inhibited 32.65\%, dichloromethane fraction (DCMF) inhibited $27.80 \%$, and aqueous fraction (AQF) inhibited $16.88 \%$ of hemolysis of RBC whereas acetylsalicylic acid exhibited $61.90 \%$ inhibition of hemolysis at normal condition. Again, in heat induced hemolysis, HF inhibited $65.21 \%$, CHF inhibited $61.47 \%$, DCMF inhibited $51.22 \%$, and AQF inhibited $22.68 \%$ of hemolysis of RBC while the acetylsalicylic acid showed $42.00 \%$ inhibition of hemolysis at normal condition.

\section{Conclusions}

The ethylacetate extract of the roots of $A$. spinosus was subjected to different chromatographic separation techniques to isolate secondary metabolites and the isolated compounds were namely stigmasterol, 1-Eicosanol, and oleic acid. The structures of the isolated compounds were elucidated by analyzing their different spectroscopic data (FT-IR, ${ }^{1} \mathrm{H}-\mathrm{NMR}$, and ${ }^{13} \mathrm{C}-\mathrm{NMR}$ ). FA analysis of the plant material revealed that USFAs were higher than SFAs. The results of In Vitro membrane stabilizing activity have provided a reasonable indication that methanol extract of roots of $A$. spinosus possess significant anti-inflammatory activity. However, further investigations are required to isolate and characterize the active therapeutics accountable for this property.

\section{Reference}

1. Kirtikar, K.R. and B.D. Basu, 1918. Indian medicinal plants, international book distributors. Dehradun, India, 1038-1063.

2. Fariba, M. H., 2016. An observation of an unusual therapeutic use of Amaranthus spinosus L. (Amaranthaceae) by the Garo tribe of Bangladesh. Asian J. Pharmacogn. 1(1), $19-21$.

3. Zeashan, H., Amresh, G., C.V. Rao and S. Singh, 2009. Antinociceptive activity of Amaranthus spinosus in experimental animals. J. Ethnopharmacol. 122(3), 492-496.

4. Kirtikar, K. R., B.D. Basu, and I. CS, 2001. Indian medicinal plants, oriental enterprises. 6, Dehradun, India, 2029-2035.

5. Ghani, A., 2003. Medicinal Plants of Bangladesh with Chemical Constituents and Uses. Asiatic Society of Bangladesh, Dhaka, 81.

6. Duke, J.A. and E.S. Ayensu, 1985. Medicinal plants of China. Reference Publ. Inc., Algonac, MI.

7. Sangameswaran, B., and B. Jayakar, 2008. Anti-diabetic, anti-hyperlipidemic and spermatogenic effects of Amaranthus 
spinosus Linn. on streptozotocin-induced diabetic rats. J. Nat. Med. 62(1), 79-82.

8. Olajide, O.A., B.R. Ogunleye and T.O. Erinle, 2004. Antiinflammatory properties of Amaranthus spinosus leaf extract. Pharm. Bio. 42(7), 521-525.

9. Kumar, B.A., K. Lakshman, C. Velmurugan, S.M. Sridhar and S. Gopisetty, 2014. Antidepressant activity of methanolic extract of Amaranthus spinosus. Basic Clin. Neurosci. 5(1), 11.

10. Amabye T. G., 2015. Evaluation of physiochemical, phytochemical, antioxidant and antimicrobial screening parameters of Amaranthus spinosus leaves. Nat. Pro. Chem. Res. 4(199), 1-5.

11. Olufemi, B.E., I. E. Assiak, G.O. Ayoadi and M.A. Onigemo, 2003. Studies on effects of Amaranthus spinosus leaf extract on the haematology of growing pigs. Afr. J. Biomed. Res. 6(3), 149-150.

12. Hilou, A., O.G. Nacoulma and T.R. Guiguemd, 2006. In Vitro antimalarial activities of extracts from Amaranthus spinosus L. and Boerhaavia erecta L. in mice. J. Ethnopharmacol. 103(2), 236-240.

13. Rastogi, R.P. and B.N. Mehrotra, 1990. Compendium of Indian medicinal plants, vol. 1. CSIR, New Delhi, 118-122.
14. Edeoga, H.O., D.E. Okwu and B.O. Mbaebie, 2005. Phytochemical constituents of some Nigerian medicinal plants. Afr. J. Biotechnol. 4(7), 685-688.

15. Rahman, M. H., M. A. Rashid and T. A. Chowdhury, 2019. Studies of Biological Activities of the Roots of Bombax ceiba L. Bangladesh Pharm. J. 22(2), 219-223.

16. Reza, M.S.A., M.H. Rahman and T.A. Chowdhury, 2020. Isolation of Secondary Metabolites from Leucas aspera and Investigation of Biological Activity. Dhaka Univ. J. Sci. 68(1), 101-104.

17. Lia, F., B. Vella, M.Z. Mangion and C. Farrugia, 2020. Application of ${ }^{1} \mathrm{H}$ and ${ }^{13} \mathrm{C}-\mathrm{NMR}$ Fingerprinting as a Tool for the Authentication of Maltese Extra Virgin Olive Oil. Foods, 9(6), 689.

18. Ji, S.H., J.W. Lee, S.E. Lee, Y.S. Lee, G.S. Kim, Y.S. Ahn, N.I. Baek, Y. Lee, H.B. Lim and D.Y. Lee, 2016. Isolation and Identification of Secondary Metabolites from the Ovary of Nelumbo nucifera. J. Life Sci. 26(10), 1196-1201.

19. Di Pietro, M.E., A. Mannu and A. Mele, 2020. NMR Determination of Free Fatty Acids in Vegetable Oils. Processes, 8(4), 410.

20. Shinde, U.A., A.S. Phadke, A.M. Nair, A.A. Mungantiwar, V.J. Dikshit and M.N. Saraf, 1999. Membrane stabilizing activity - a possible mechanism of action for the antiinflammatory activity of Cedrus deodara wood oil. Fitoterapia, 70(3), 251-257. 